\title{
An Analysis of Students' Ability in Using Punctuation Marks in Descriptive Paragraph Writing
}

\author{
Fiber Yun Ginting \\ FKIP of Catolic University of Saint Thomas Medan Indonesia \\ Email; teozam@ymail.com
}

\begin{abstract}
Punctuation is one of the most important aspects of written English, and yet it is one that is taken the most lightly. It is, in fact, this feature of writing that gives meaning to the written words much like pauses and changes in tones of the voice when speaking. This study also has objective to explore the ability of students in placing punctuation marks in descriptve paragraph.The writer used descriptive qualitative research to give description systematically and factually about facts of a certain population. This research only describes how the students' ability in using punctuation mark in writing descriptive paragraph.The students' ability in using punctuation marks in descriptive writing was categorized into low, It can be classified that only 1 (one) students or 2\% was categorized into excellent who got score 80 from the total students were 53 students, and 10 (ten) students or 10\% were categorized into Good, 17 (seventeen) students or 32\% were categorized into fair, 13 (thirteen) students or $24.5 \%$ were categorized into Low, and 12 (twelve) students or $22.5 \%$ were categorized into Failed.
\end{abstract}

Keywords: punctuation marks; paragraph writing; descriptive

\section{Introduction}

Writing is a communication competence between the writer and the readers. The writer has to express her/his ideas with a good writing to reach a goal of writing. To write well or to get a good writing, the writer has to anticipate the reactions of the reader.Therefore, in writing, the students can devote some ideas in their mind on a piece of paper, they can write something that they cannot talk, so, their idea can be understood by the reader. To make a good paragraph writing, the students must pay attention in using many aspect influence writing. As well as Harmer (2004) consider punctuation as one of the important feature of writing and using punctuation correctly is an important skill many people judge the quality of what is written not just on the content, the language but also on the use of punctuation, if capital letters, commas, full stop, sentence and paragraph boundaries, etc. So, Punctuation is one of the most important aspects of written English, and yet it is one that is taken the most lightly. It is, in fact, this feature of writing that gives meaning to the written words much like pauses and changes in tones of the voice when speaking.As crystal (2003) state punctuation plays a critical role in the modern system, yet its significance is regularly understood. In other words, if punctuation marks in the text are not properly used, the readers may have difficulties to understand the text. Similarly, an error in punctuation can convey a completely different meaning to the one that is intended. 
For example:

He was bitten by a dog which hurt him.

He was bitten by a dog, which hurt him.

The first sentence means the dog hurt him. The second sentence means the bite hurts him. It's the comma after the dog that has completely changed the meaning of the sentence. From the examples above, we can see how punctuation has made the same mean two exactly opposite things. It's very important to know all the punctuation marks, their meanings, and when to use them in order to produce a good piece of writing and more importantly, to convey the correct message.Therefore, from the explanation above, the problem in this study is how good the students in using punctuation marks in descriptive paragraph writing of the students of English Education Program at FKIP UNIKA Medan. This study also has objective to explore the ability of students in placing punctuation marks in descriptve paragraph.

Meanwhile, Graham and Perin (2007) state that writing is a skill that draws on the use of strategies (such as Planning, evaluating, and revising text) to accomplish a variety of goals, such as writing a report or expressing an opinion with the support of evidence.Therefore, to write correctly, the students should have good ability in writing process so that the readers are interested in reading their writing and understand the message clearly.This is in line with Harmer (2004) who states that being able to write is a vital for speakers of foreign language as much as for everyone using their own first language. It means that writing is an important skill because it is also the basic skill for students to communicate with others in written form.Dorothy (2003) states a descriptive paragraph describes a person, place, or thing. The writer use the five senses and figurative language including personification, onomatopoeia, and comparisons when writing descriptive paragraph.

\section{The Concept Problem in Writing}

Martin (1994) states writing is a process of transferring ideas into written from which is understandable. The students should understand about generic structure, and language feature of the text. The students also should pay attention about content, organization, vocabulary, language, and mechanism when writing a text. Writing is skill which is important to be mastered as well. As the writer, she/he should know how to develop paragraph into good composition. It included the ideas, unity of paragraph, sentences pattern, grammar, correct punctuation, spelling, and capitalization.

\subsection{Punctuation in Writing}

Kane (2000) states all punctuation exist, basically, to help readers understand what you wish to say. It means that punctuation is sign that show what the appropriate expression with the sentence that have been built by the writer. It is supported by Jackson (2005) the purpose of punctuation is to enable your reader to interpret unambiguously the structure, and therefore the meaning, of your writing. The absence of full stop to distinguish the sentences in the email above is, in effect, an insult to the readers. Poorly punctuated writing can make frustrated and annoyed readers. Mary (1998) states punctuation is placed in text to make meaning clear and to make reading easier. The various punctuation marks perform four functions: they (1) separate (a period separates sentences), (2) group or enclose (parentheses 
enclose extraneous information), (3) connect (a hyphen connects a unit modifier), and (4) impart meaning (a question mark may make an otherwise declarative sentence interrogative). The function of a punctuation mark is the basis for the rules governing its use and should be the basis for determining whether or not it is needed.

According to Zuzana (2000) proper punctuation makes a text clear to understand. Wrongly placed punctuation marks may make a sentence ambiguous or even change the meaning. Apart from capital letters and full stops, the most common punctuation marks in technical and scientific writing are:

$\begin{array}{ll}\text { Comma } & (,) \\ \text { Colon } & (:) \\ \text { Semi-colon } & (;)\end{array}$

Bracket/parenthesis () []

Dash

Hyphen

Apostrophe

\section{Research Method}

In this study, the writer used descriptive qualitative research to give description systematically and factually about facts of a certain population. Descriptive qualitative research is not generally directed toward hypothesis testing, the aim is to describe what exist with respect to variables or condition in a situation. This research only describes how the students' ability in using punctuation mark in writing descriptive paragraph. The population in this research were the students of English Education Study Program at FKIP UNIKA Medan in Academic Year 2017/2018that consist of three classes; Second semester, fourth semester, and sixth semester class with the total sample 53 students as the population.. The researcher gave the descriptive paragraph with the blank punctuation and the students to complete the descriptive paragraph with the correct punctuation. The students had 90 minutes to finished the test.

Table 1. The Frequency of Punctuation Mark in the Test

\begin{tabular}{|l|l|c|}
\hline No. & \multicolumn{1}{|c|}{ Punctuation Mark } & Frequency \\
\hline 1. & Exclamation & 2 \\
\hline 2. & Bracket & 4 \\
\hline 3. & Capital letter & 8 \\
\hline 4. & Comma & 9 \\
\hline 5. & Quotation & 4 \\
\hline 6. & Full stop & 7 \\
\hline 7. & Apostrophe & 5 \\
\hline 8. & Hyphen & 6 \\
\hline 9 & Colon TOTAL & $\mathbf{4 9}$ \\
\hline & \multicolumn{2}{|c|}{} \\
\hline
\end{tabular}

After the researcher analyzed the punctuation used by students in descriptive paragraph, the researcher classified the level of students' ability based on the classification as follow: 
Table2The Classification of Students' ability in Using Punctuation Mark

\begin{tabular}{|c|c|}
\hline Students' Ability & Level of Ability \\
\hline $80-100$ & Excellent \\
\hline $66-79$ & Good \\
\hline $56-65$ & Fair \\
\hline $46-55$ & Low \\
\hline $0-45$ & Failed \\
\hline
\end{tabular}

The ability and the errors then counted and tabulated, and the number of the ability and the errors is presented in form of percentage. To find the percentage of frequency in each type of the ability and the errors, the formula used is as follows:

$$
\begin{gathered}
\mathrm{P}=\underline{\mathrm{F}} \times 100 \% \\
\mathrm{P}=\text { Percentage (Students ability) } \\
\mathrm{F}=\text { Frequency (Students' score) } \\
\mathrm{N}=\text { Total Number of Students (Respondents) }
\end{gathered}
$$

\section{Result and Discussion}

There were nine indicator items of punctuation marks which are used as an instrument of this research. They are exclamation, bracket, capital letter, comma, quotation, full stop, apostrophe, hyphen and colon. After giving the test, the researcher gets 2597 answer, and then the researcher checks the student's works. From the student answer sheets, the researcher found 1153 incorrect or errors and 1444 correct answer.

The frequencies of the students ability in using punctuation marks in descriptive writing is presented on the following table.

Table 3. The Students' answer sheets

\begin{tabular}{|l|l|c|c|c|}
\hline No. & \multicolumn{1}{|c|}{ Punctuation Mark } & Item & Emerge & $\begin{array}{c}\text { Correct } \\
\text { Answer }\end{array}$ \\
\hline 1. & Exclamation & 2 & 106 & 47 \\
\hline 2. & Bracket & 4 & 212 & 48 \\
\hline 3. & Capital letter & 8 & 424 & 347 \\
\hline 4. & Comma & 9 & 477 & 129 \\
\hline 5. & Quotation & 4 & 212 & 64 \\
\hline 6. & Full stop & 7 & 371 & 250 \\
\hline 7. & Apostrophe & 6 & 265 & 165 \\
\hline 8. & Hyphen & 4 & 212 & 206 \\
\hline 9 & Colon TOTAL & $\mathbf{4 9}$ & $\mathbf{2 5 9 7}$ & 188 \\
\hline \multicolumn{2}{|c|}{} \\
\hline
\end{tabular}

In the table above, it is clear that the total of the correct answer of punctuation marks from each item can be seen there were 1444 frequencies that emerge in the test from the total of items about 2597 items. In this research, the researcher found the percentage of students' ability in using punctuation marks in writing descriptive writing by using the formula:
Percentage = The Correct Answer $X 100 \%$ 


\section{Total punctuation mark emerge}

$\begin{array}{ll}\text { 1. Exclamation } & =\frac{47}{106} \times 100 \%=44.4 \% \\ \text { 2. Bracket } & =\frac{48}{212} \times 100 \%=22.7 \% \\ \text { 3. Capital letter } & =\frac{347}{424} \times 100 \%=82 \% \\ \text { 4. Comma } & =\frac{129}{477} \times 100 \%=28 \% \\ \text { 5. Quotation } & =\frac{64}{212} \times 100 \%=30.2 \% \\ \text { 6. Full Stop } & =\frac{250}{371} \times 100 \%=67.4 \% \\ \text { 7. Apostrophe } & =\frac{165}{265} \times 100 \%=62.3 \% \\ \text { 8. Hyphen } & =\frac{206}{318} \times 100 \%=64.8 \% \\ \text { 9. Colon } & =\frac{188}{212}\end{array}$

It was clearly seen in the percentage calculation above that the colon $(89 \%)$ Is the Highest and followed by capital letter (82\%), Full Stop (67.4\%), Hyphen (64.4\%), and apostrophe $(62.3 \%)$.For more detail, it can be seen in the following.

Table 4. The Percentage of Punctuation Ability

\begin{tabular}{|l|l|c|c|}
\hline No. & Punctuation Mark & Frequency & $\begin{array}{c}\text { Percentage } \\
\mathbf{\%}\end{array}$ \\
\hline 1. & Exclamation & 47 & $44.4 \%$ \\
\hline 2. & Bracket & 48 & $22.7 \%$ \\
\hline 3. & Capital letter & 347 & $82 \%$ \\
\hline 4. & Comma & 129 & $28 \%$ \\
\hline 5. & Quotation & 64 & $30 \%$ \\
\hline 6. & Full stop & 250 & $67.4 \%$ \\
\hline 7. & Apostrophe & 165 & $62.3 \%$ \\
\hline 8. & Hyphen & 206 & $64.8 \%$ \\
\hline 9 & Colon & 188 & $89 \%$ \\
\hline
\end{tabular}

Based on the result of test, there are 49 frequencies of punctuation marks that students must be completed in the test. There is only 1 (one) student who got score 80 categorized into excellent, 10 (ten) students got score 66 to 79 categorized into Good, 17 (seventeen) students who got score 56 to 65 categorized into Fair, 13 (thirteen) students who got score 46 to 55 categorized into Low, and 12 (twelve) students who got score 0 to 45 categorized into Failed.

Table 5.The Result of student's ability in using Punctuation Marks

\begin{tabular}{|l|c|c|}
\hline Students scores & Frequency & Level ability \\
\hline $80-100$ & 1 & Excellent \\
\hline $66-79$ & 10 & Good \\
\hline
\end{tabular}




\begin{tabular}{|l|c|c|}
\hline $56-65$ & 17 & Fair \\
\hline $46-55$ & 13 & Low \\
\hline $0-45$ & 12 & Failed \\
\hline
\end{tabular}

The percentage of classification after the students' ability was classified; the researcher used the formula to count the percentage of the level ability.

1. The percentage of students' classification Excellent:

$$
\mathrm{P}=\frac{1}{53} \times 100 \%=2 \%
$$

2. The percentage of students' classification Good:

$$
\mathrm{P}=\frac{10}{53} \times 100 \%=19 \%
$$

3. The percentage of students' classification Fair:

$$
\mathrm{P}=\underline{17} \times 100 \%=32 \%
$$

53

4. The percentage of students' classification Low:

$$
\mathrm{P}=\frac{13}{53} \times 100 \%=24.5 \%
$$

5. The percentage of students' classification Failed:

$$
\mathrm{P}=\frac{10}{53} \times 100 \%=22.5 \%
$$

For more detail, it can be seen in the following table:

Table 6. the frequencies Percentage of student's ability in using Punctuation Marks

\begin{tabular}{|l|c|c|}
\hline Students scores & Frequency & Percentage \\
\hline $80-100$ & 1 & $2 \%$ \\
\hline $66-79$ & 10 & $19 \%$ \\
\hline $56-65$ & 17 & $32 \%$ \\
\hline $46-55$ & 13 & $24.5 \%$ \\
\hline $0-45$ & 12 & $22.5 \%$ \\
\hline Total & $\mathbf{5 3}$ & $\mathbf{1 0 0} \%$ \\
\hline
\end{tabular}

\section{Conclusion}

The students' ability in using punctuation marks in descriptive writing was categorized into low, since the mean of the students was 55.47. it was because most of the students were unable to know the function of punctuation marks in writing paragraph. It can be classified that only 1 (one) students or $2 \%$ was categorized into excellent who got score 80 from the total students were 53 students, and 10 (ten) students or $10 \%$ were categorized into Good, 17 (seventeen) students or 32\% were categorized into fair, 13 (thirteen) students or $24.5 \%$ were categorized into Low, and 12 (twelve) students or $22.5 \%$ were categorized into Failed.

\section{References}

Crystal, D. 2003. A Dictionary of Linguistics and Phonetics. Oxford: Oxford Basil Blackwell 
Dorothy P. Hall, et al. 2003. Writing Mini-Lesson for upper Grades: The Big-Blocks Approach. North Carolina: Carson-Dellosa Publishing Company, Inc.

Graham, S. \& Perin, D. 2007. Writing Text: Effective Strategies To Improve Writing Of Adolescents In Middle And High Schools. New York: Alliance for Excellent Education.

Harmer, J. 2004. How to teach Writing. United Kingdom: Longman

Kane, T, S., 2000. The oxford: essential guide to writing. The Berkley Publishing Group: New York

Mary, K. Mccastill. 1998. Grammar, Punctuation, and Capitalization: A Handbook for Technical Writer and Editor. Virginia: Langley Research Center

Martin H. Manser. 1994. Oxford Advanced Learner's Dictionary of Current English. New York: Oxford University Press. 